Research Article

\title{
Comparison of Knowledge and Attitude regarding Reproductive Health between Adolescent Girls of Urban and Rural Schools in West Bengal
}

\author{
Sneha Roy', Lakhsmi Pandit', Purnima Kundu', Kabita Nandi ${ }^{4}$
}

${ }^{1}$ Tutor, Department of Obstetrics and Gynaecology, Apollo Gleneagles Nursing College, Kolkata, India.

${ }^{2}$ Reader, ${ }^{3,4}$ Professor, Department of Medical Surgical Nursing, Government College of Nursing, BSMC, Bankura, Kolkata, India. DOI: https://doi.org/10.24321/2348.2141.202106

I $\quad \begin{array}{lllll}\mathbf{N} & \mathbf{F} & \mathbf{O}\end{array}$

Corresponding Author:

Sneha Roy, Department of Obstetrics and Gynaecology, Apollo Gleneagles Nursing College, Kolkata, India.

E-mail Id:

sroy0938@gmail.com

Orcid Id:

https://orcid.org/0000-0002-1015-5327

How to cite this article:

Roy S, Pandit L, Kundu P, Nandi K. Comparison of Knowledge and Attitude regarding Reproductive Health between Adolescent Girls of Urban and Rural Schools. Trends Nurs Adm Edu. 2021;10(2):6-16.

Date of Submission: 2021-08-03

Date of Acceptance: 2021-08-21
$\begin{array}{llllllll}\mathbf{A} & \mathbf{B} & \mathbf{S} & \mathbf{T} & \mathbf{R} & \mathbf{A} & \mathbf{C} & \mathbf{T}\end{array}$

Introduction: Adolescents can be key driving forces in building a future of dignity for all. They are an important resource for any country. Reproductive health covers all aspects of adolescent health. In order to lead healthy, responsible, and fulfilling lives, and to protect themselves from reproductive health problems, youngsters need adequate information about the physical and psychological changes that take place during puberty, menstruation, pregnancy and childbirth.

Methods: A comparative survey was conducted among 90 randomly selected adolescent girls from urban and rural schools of Bankura, West Bengal. Information was collected by administering structured knowledge questionnaire and 5-point attitude rating scale.

Results: The findings revealed that $46.67 \%$ of girls from urban school and $51.11 \%$ of girls from rural school had excellent knowledge score and $65.56 \%$ of adolescent girls from urban school had positive and $61.11 \%$ of girls from rural school had fair attitude score towards reproductive health. There was no significant difference in knowledge score $(t=$ -0.555 at $p>0.580$ ) but significant difference in attitude score $(t=4.98$ at $p<0.00$ ) was there. There was a weak positive correlation found between knowledge and attitude scores of adolescent girls in both urban $(r=0.46)$ and rural $(r=0.335)$ schools. No significant association was found between knowledge and attitude scores and demographic characteristics of adolescent girls in both schools.

Conclusion: The study concluded that there was a gap in the level of attitude of adolescent girls of urban and rural schools. So there is a need to educate adolescent girls regarding some aspects of reproductive health.

Keywords: Adolescent Girls, Reproductive Health, Knowledge, Attitude 


\section{Introduction}

Young people are the world's most unexploited resource. Adolescence is a crossroad in life, a time when future directions are determined for better or worse. They are the important resource of any country that can be the key driving force in building a future of dignity for all. As per the World Health Organization expert committee, adolescence is defined as the period between 10 and 19 years of age, which is the second decade of life. ${ }^{1}$ In a report compiled by the Family Planning Association (FPA) of India, $21 \%$ of Indian youths is between 10 and 19 years of age.

The twentieth century began with almost 1.6 billion human beings in the world, and with a growth rate of 96 million people per year, this century will end with nearly over 6 billion people. Almost $50 \%$ of this population is constituted by females. India has one of the largest populations of teenagers with a headcount of 23 million, representing over $26 \%$ of the total teenage population in the world. ${ }^{2}$

In the contemporary Indian society, urbanisation and liberal attitudes have increased the likelihood of indulging in sexual proximity at an early age, with women usually bearing the brunt of this. These factors put teenage girls at risk of unwanted pregnancy, birth defects, and reproductive organ disease. Social and psychological consequences include the discontinuation of education, forced early marriages, unplanned pregnancies, unsafe abortions, and depression. ${ }^{3}$

Healthy reproductive life includes freedom from sexually transmitted infections and the right to determine one's own fertility with full knowledge of contraceptive choices. Adolescents need to know how to protect themselves from HIV/ STD and premature pregnancies and keep up a healthy and safe sexual life. Sexual education is a critical part of lifelong learning, which is based on knowledge, skill, and positive attitude towards reproductive health. ${ }^{2,4,5}$

Adolescent health depends on the range of approaches to prevent, detect or treat young people's health or illness. During this time, a number of physiological, behavioural and psychological changes occur, the most notable being the onset of menstruation. ${ }^{6}$

The World Health Organization (WHO) defines reproductive health as a state of complete physical, mental, and social well-being, not just the absence of disease or infirmity. ${ }^{7}$

Adolescence, a stage of physiological, mental, and social transformation that accompanies inquisitiveness, impulsiveness, and experimentation, makes them prone to risky health behaviours. These behaviours make them vulnerable to diseases especially sexually transmitted diseases. ${ }^{8}$ Adolescents and youth are more at risk for STIs than older adults. Focusing on adolescent reproductive health is both a challenge as well as an opportunity for health care providers. Though adolescence is generally a healthy phase of life, many adolescents are less educated, less experienced, and less comfortable accessing health services for reproductive health than adults..$^{9,10}$

Another aspect of reproductive health is the age of marriage. Early marriage is generally associated with early childbearing and high fertility, both of which are health risks for women and their children. In terms of family planning, adolescent girls globally probably constitute the most vulnerable group as they are the victims of early marriage and premature and frequent childbearing, all of which lead to high morbidity and mortality. ${ }^{9,11}$

Adolescents often lack basic reproductive health information, knowledge, and access to affordable confidential health services for reproductive health. Lack of comprehensive sexuality education, inaccessibility, and lack of knowledge regarding contraceptives, and erroneous sex education leads to unhealthy sexual practices and reproductive illhealth.

A cross-sectional study was conducted by Grover $\mathrm{S}$ et al. (2017) among adolescent girls in Faridkot, Punjab regarding their knowledge of reproductive health, contraceptive methods, STDs including HIV/ AIDS, and HPV vaccine.

Total 400 adolescent girls of class 11th and 12th aged between 16 and 19 years, and studying in English medium schools were selected through voluntary participation. The results showed that majority of the girls $(67 \%)$ were not aware of the meaning of reproductive health. ${ }^{12}$

So there is a diversity of challenges faced by young people in regard to their reproductive health and therefore the problems with critical importance to them vary greatly depending on their cultural and geographical backgrounds. These issues include forced early marriage, lack of opportunities, unwanted pregnancy, early childbearing, the spread of HIV/ AIDS and other sexually transmitted infections, and female genital mutilation.

All these issues need to be addressed to achieve better reproductive health of adolescents. This triggered the researcher to undertake a comparative survey on knowledge and attitude regarding reproductive health among adolescent girls of urban and rural schools in the district of Bankura.

\section{Purpose of the Study}

The study was conducted with the aim of assessing and comparing the knowledge and attitude of adolescent girls regarding reproductive health and finding a relationship between their knowledge and attitude regarding reproductive health which in turn might help to prevent unintended pregnancies, improve maternal health, and diagnose and treat sexually transmitted infections including HIV/ AIDS. 


\section{Objectives of the Study}

1. To assess the knowledge and attitude towards reproductive health among adolescent girls of urban and rural schools.

2. To compare the knowledge and attitude between adolescent girls and to find out the relationship between knowledge and attitude of urban and rural schools.

3. To determine an association between knowledge and attitude towards reproductive health and demographic factors among adolescent girls.

\section{Materials and Methods}

\section{Study Design and Study Setting}

A descriptive cross-sectional comparative study was conducted in a setting of urban-rural schools of Bankura, West Bengal during the period from January 2020 to February 2020.

\section{Sample Size and Sampling}

Literature review reveals that the prevalence of knowledge regarding reproductive and sexual health among school going adolescents in India is $35 \% .{ }^{6}$ Considering this, by using the formula $n=Z^{2} p q / d^{2}$, and allowable error of $10 \%$, the estimated sample size for our study was 178 and it was rounded off to 180 .

In this study, for the selection of a school, purposive sampling technique was applied, and a simple random sampling (Slip bag technique without replacement) was adopted to select the sample based on inclusion and exclusion criteria of the study.

\section{Method of Data Collection}

Information was collected by using paper-pencil test based on a structured, pre-tested questionnaire. Pre-testing was done on adolescents falling in the same age group (10-19 years), in a similar setting, to screen for potential problems in the questionnaire.

\section{Inclusion Criteria}

The study included adolescent girls who were:

- Present during the data collection period

- Willing to participate in the study

- Able to communicate and understand Bengali

\section{Exclusion Criteria}

The study excluded the adolescents who were:

- Diagnosed with mental disease(s)

\section{Questionnaire and Study Variables}

The questionnaire had three parts. In the first part, the semi-structured questionnaire was adopted to collect demographic data of respondents. The second part consisted of a structured knowledge questionnaire to assess the knowledge of adolescent girls regarding reproductive health. It consisted of 30 items about different aspects of knowledge related to reproductive health which included menstruation, pregnancy, contraception, and sexually transmitted infections. The third part of the questionnaire consisted of structured questions to elicit their attitude regarding reproductive health. Socioeconomic status (SES) was estimated according to modified BG Prasad classification.

\section{Ethical Consideration}

Permission was taken from the Institutional Ethics Committee of BSMC, Bankura, Principal of Government College of Nursing, BSMC, Bankura, District Inspector of Schools (Secondary Education), Bankura, and also from Head Mistress of respective girls' schools. Written informed consent was obtained from participants regarding their willingness to participate in the study.

\section{Statistical Analysis}

The data analysis was planned to include descriptive and inferential statistics and data were analysed with the help of statistical software SPSS version 23.

\section{Results}

The data presented in Table 1 depict that majority (44.45\%) of the adolescent girls from urban schools were 14 years old, whereas, in rural schools, majority $(46.67 \%)$ of the adolescent girls were 15 years old.

Fathers of majority of the adolescent girls from both urban $(35.56 \%)$ and rural (36.67\%) schools were educated up to the secondary level. Mothers of majority (37.78\%) of the adolescent girls from the urban school were educated up to the primary level whereas mothers of majority $(42.22 \%)$ of the adolescent girls from the rural school were educated up to the secondary level. Table 1 also shows that the majority (28.89\%) of adolescent girls from the urban school belonged to the upper-middle socioeconomic class whereas the majority (26.67\%) of adolescent girls from rural schools belonged to the middle socioeconomic class.

Data presented in Table 2 reveal that the majority of adolescent girls from both urban (46.67\%) and rural (51.11\%) schools had excellent knowledge regarding reproductive health and only $1.11 \%$ of adolescent girls from the urban school and $3.33 \%$ of adolescent girls from the rural school had average knowledge regarding reproductive health. None of the adolescent girls from both urban and rural schools had poor level of knowledge regarding reproductive health. It also depicts that in the urban school, majority (65.56\%) of the adolescent girls had a positive attitude towards reproductive health whereas, in the rural school, majority $(61.11 \%)$ of the adolescent girls had a fair attitude regarding reproductive health. 
Table I.Socio-demographic Characteristics of the Adolescent Girls of Selected Urban and Rural Schools

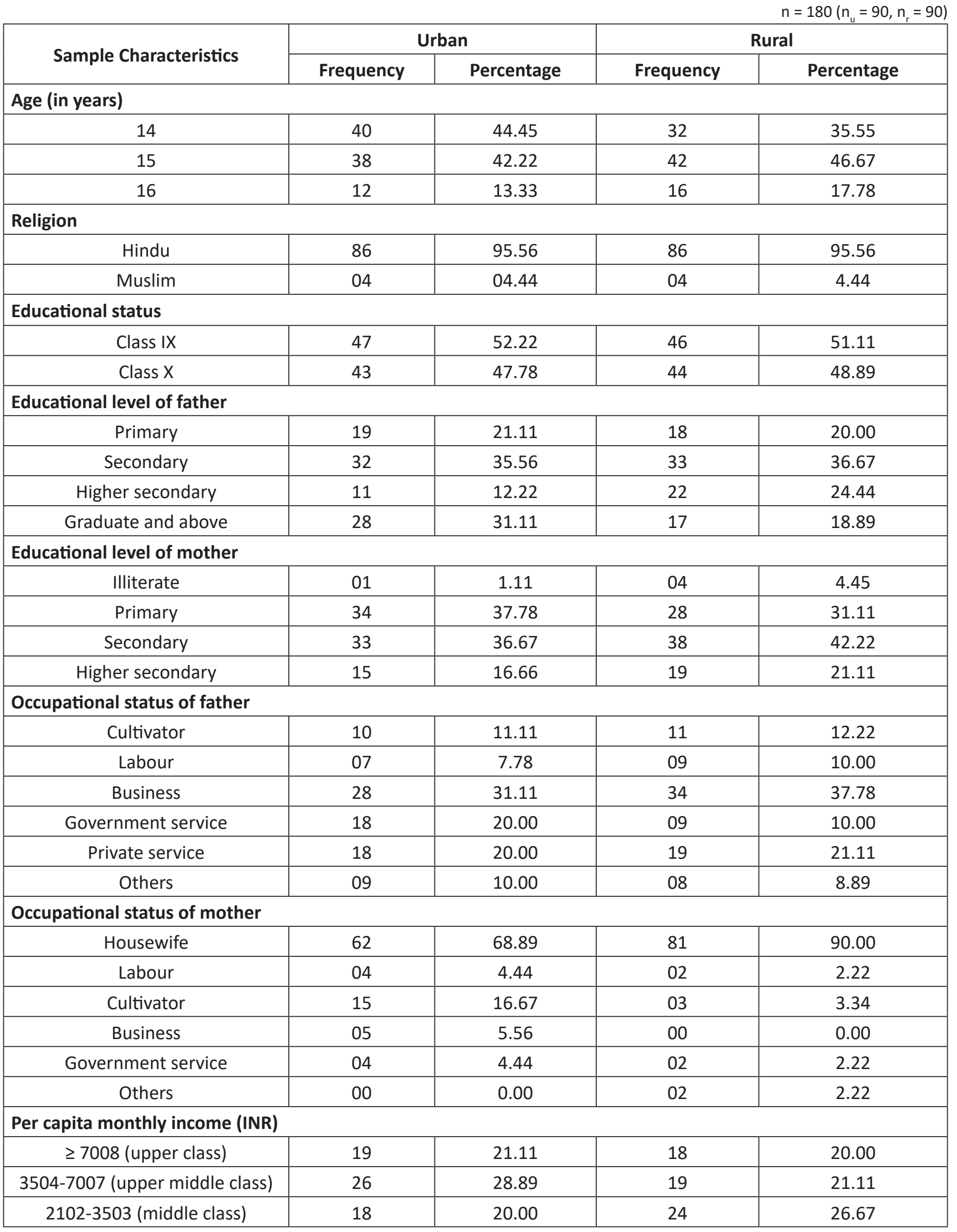




\begin{tabular}{|c|l|l|l|l|}
\hline $1051-2101$ (lower middle class) & 16 & 17.78 & 18 & 20.00 \\
\hline$\leq 1050$ (lower class) & 11 & 12.22 & 11 & 12.22 \\
\hline
\end{tabular}

$\mathrm{n}_{\mathrm{u}}$ : Number of urban adolescent girls, $\mathrm{n}_{\mathrm{r}}$ : Number of rural adolescent girls

Table 2.Frequency and Percentage Distribution of Adolescent Girls according to their Level of Knowledge and Attitude regarding Reproductive Health

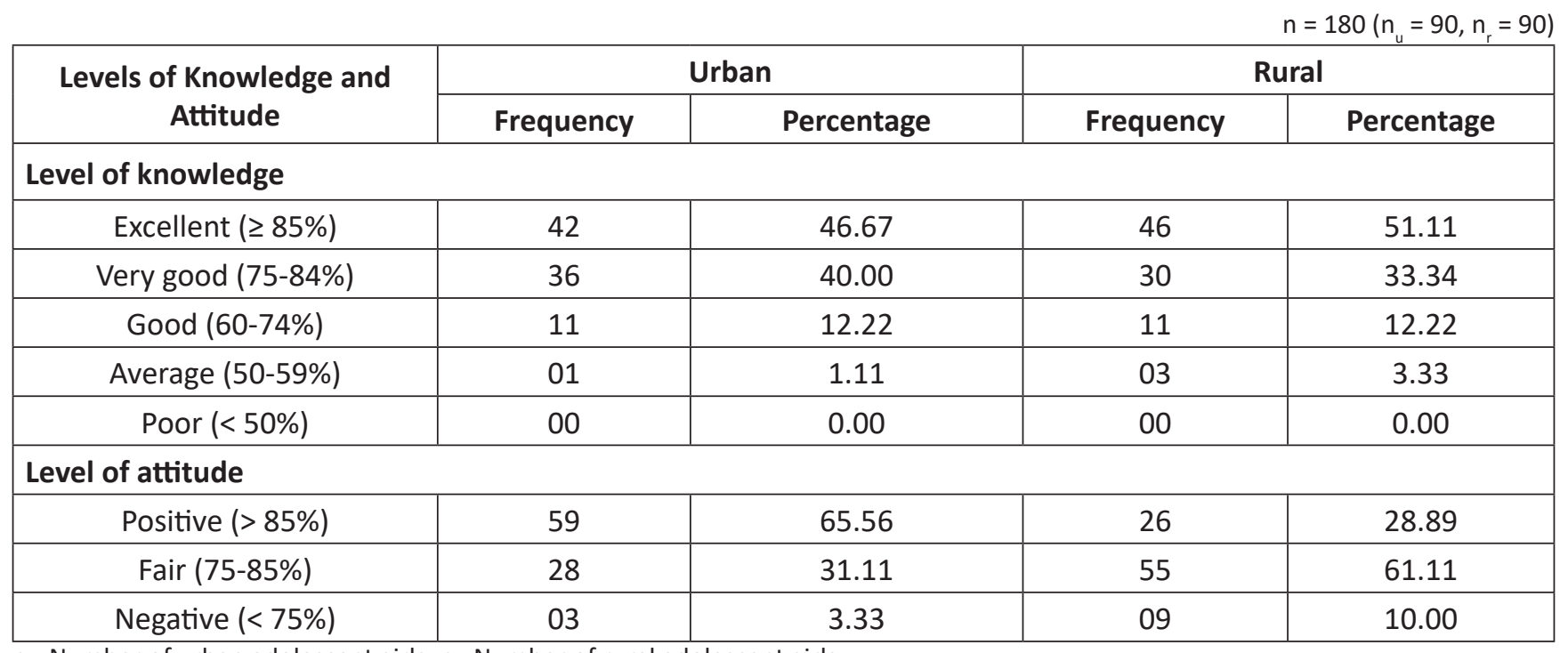

$n_{u}:$ Number of urban adolescent girls, $n_{r}$ : Number of rural adolescent girls

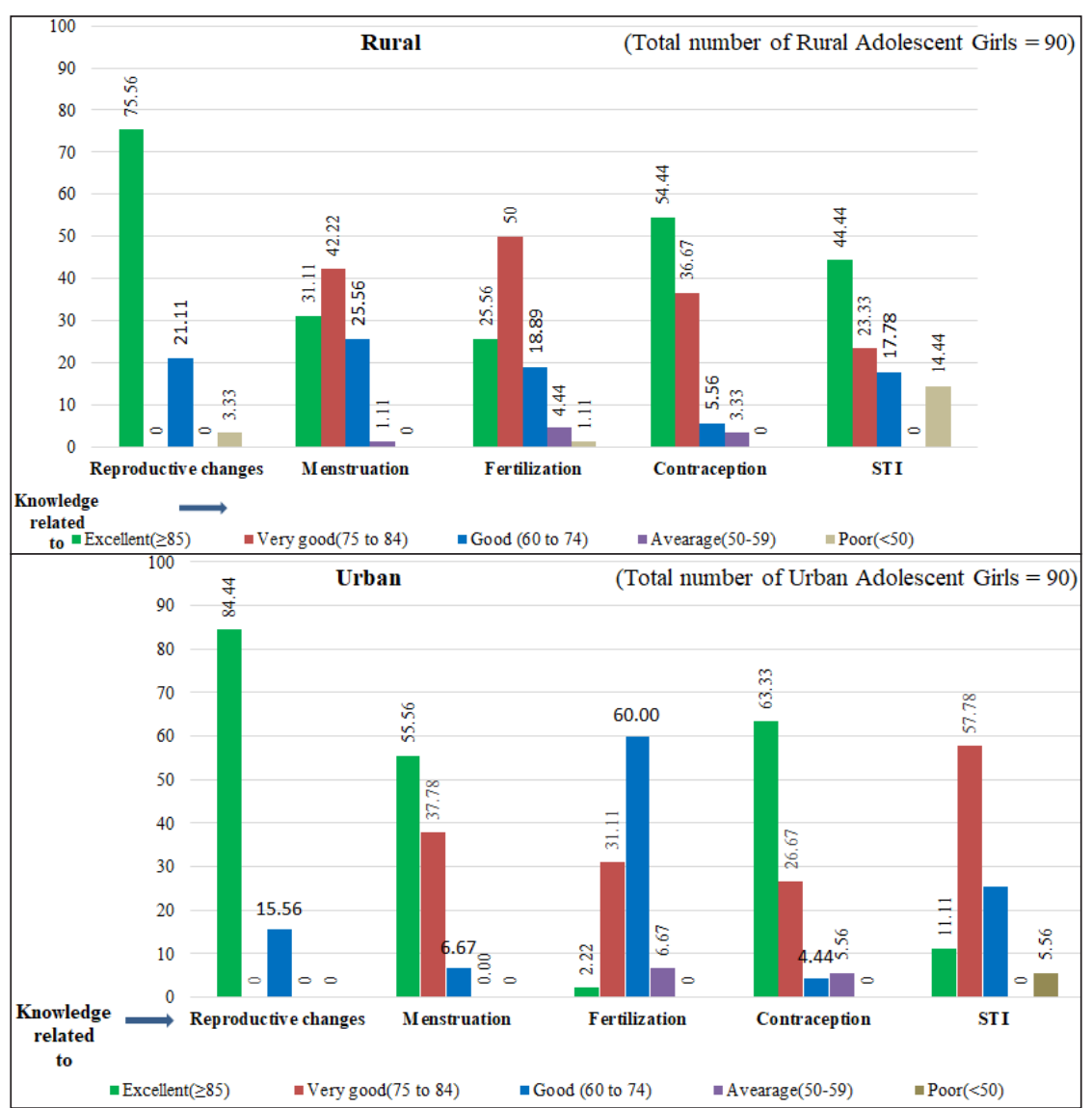

Figure I.Distribution of Knowledge Score of Adolescent Girls (Rural and Urban) regarding Reproductive Health 
Figures 1 and 2 show area wise distribution of knowledge and attitude scores of adolescent girls of rural and urban schools regarding reproductive health.

The data mentioned in Table 3 reveal that the mean knowledge score $(25.07 \pm 2.63)$ of adolescent girls from the rural school was slightly higher than the mean knowledge score $(24.87 \pm 2.17)$ of adolescent girls from the urban school. There was no significant difference between the knowledge scores of adolescent girls of urban and rural schools regarding reproductive health.

It also depicts that the mean attitude score $(86.32 \pm 4.53)$ of adolescent girls from the urban school was higher than the mean attitude score $(82.38 \pm 5.96)$ of adolescent girls from the rural school. There was a significant difference between the attitude score of adolescent girls of urban and rural schools regarding reproductive health.
The data presented in Table 4 show that in the urban school, the correlation between knowledge and attitude scores of adolescent girls was 0.46 which was moderately positive, and in the rural school, it was 0.335 which was weakly positive and significant at 0.01 level of significance.

Tables 5 and 6 show that there was no significant association of knowledge score of the adolescent girls with selected socio-demographic variables regarding reproductive health in the urban and rural schools respectively, as is evident from the calculated chi-square values at 0.05 level of significance.

Data presented in Tables 7 and 8 show that there was no significant association of attitude score of adolescent girls with selected socio-demographic variables regarding reproductive health in the urban and rural schools respectively, as is evident from the calculated chi-square values at 0.05 level of significance.

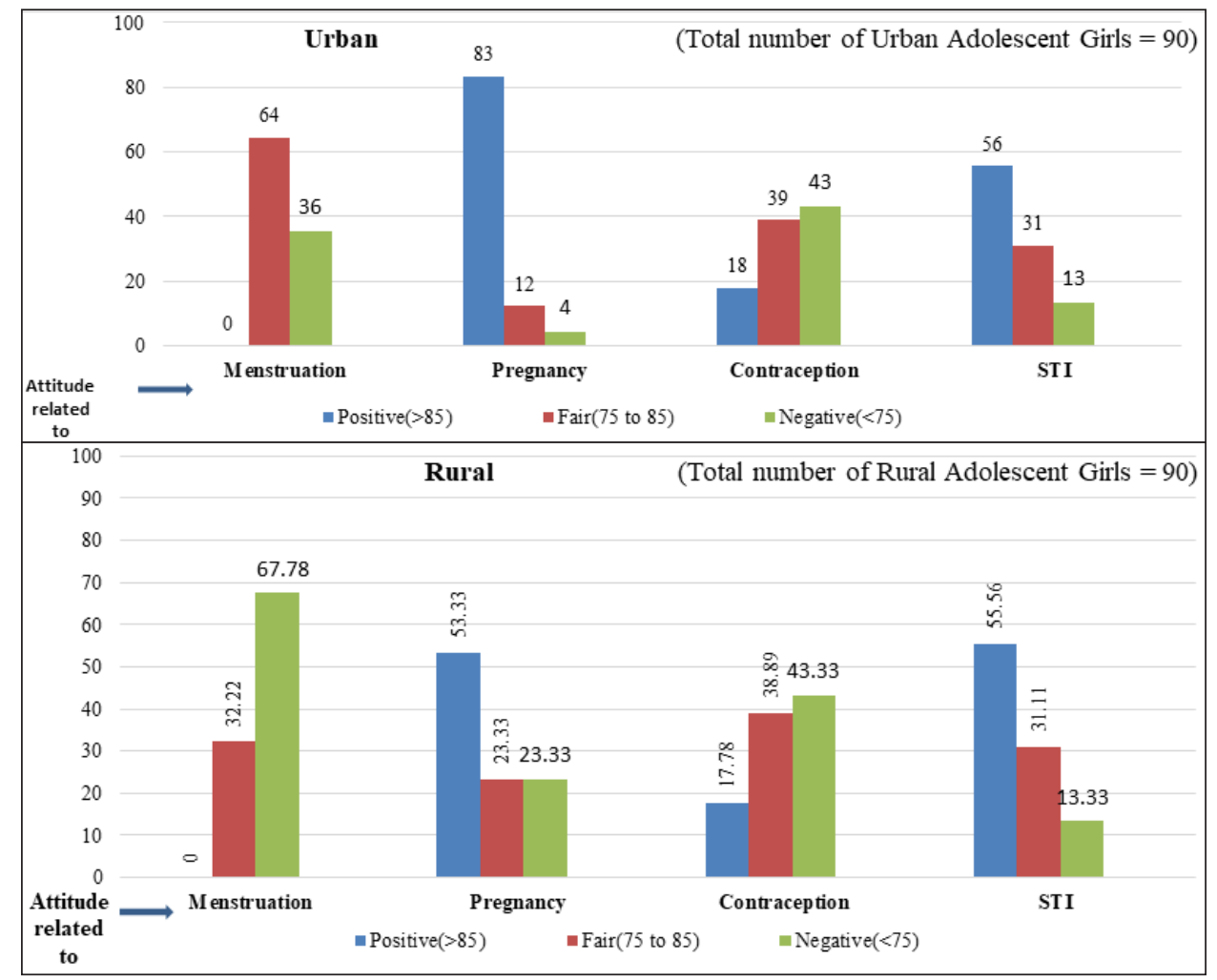

Figure 2.Level of Attitude of Adolescent Girls (Urban and Rural) regarding Reproductive Health

Table 3.Comparison of Knowledge and Attitude Scores of Adolescent Girls of Urban and Rural Schools regarding Reproductive Health

\begin{tabular}{|c|c|c|c|c|c|c|c|c|c|}
\hline Scores & Resident & Mean & $\begin{array}{c}\text { Mean } \\
\text { Difference }\end{array}$ & Median & $\begin{array}{l}\text { Standard } \\
\text { Deviation }\end{array}$ & $\begin{array}{c}\text { Standard } \\
\text { Error }\end{array}$ & $\begin{array}{c}\text { "t" } \\
\text { value }\end{array}$ & $d f$ & $\begin{array}{c}\mathbf{P} \\
\text { Value }\end{array}$ \\
\hline \multirow{2}{*}{$\begin{array}{l}\text { Knowledge } \\
\text { Score }\end{array}$} & Urban & 24.87 & \multirow{2}{*}{-0.2} & 25 & 2.17 & 0.229 & \multirow{2}{*}{-0.555} & \multirow{2}{*}{178} & \multirow{2}{*}{0.580} \\
\hline & Rural & 25.07 & & 26 & 2.63 & 0.277 & & & \\
\hline
\end{tabular}




\begin{tabular}{|c|c|c|c|c|c|c|c|c|c|}
\hline \multirow{2}{*}{$\begin{array}{c}\text { Attitude } \\
\text { Score }\end{array}$} & Urban & 86.32 & \multirow[b]{2}{*}{3.94} & 88 & 4.53 & 0.477 & \multirow[b]{2}{*}{4.98} & \multirow[b]{2}{*}{178} & \multirow[b]{2}{*}{0.00} \\
\hline & Rural & 82.38 & & 83 & 5.96 & 0.628 & & & \\
\hline
\end{tabular}

$\mathrm{n}_{\mathrm{u}}:$ Number of urban adolescent girls, $\mathrm{n}_{\mathrm{r}}$ : Number of rural adolescent girls

Table 4.Correlation between Knowledge and Attitude Scores of Adolescent Girls of Urban and Rural Schools regarding Reproductive Health

$\mathrm{n}=180\left(\mathrm{n}_{4}=90, \mathrm{n}_{\mathrm{r}}=90\right)$

\begin{tabular}{|c|c|c|c|c|c|}
\hline Resident & Mean Knowledge Score & Mean Attitude Score & df & Correlation Coefficient & P Value \\
\hline Urban & 24.87 & 86.32 & \multirow{2}{*}{88} & 0.46 & 0.00 \\
\cline { 1 - 3 } \cline { 5 - 7 } & 25.07 & 82.39 & & 0.335 & 0.001 \\
\hline
\end{tabular}

$\mathrm{n}_{\mathrm{u}}$ : Number of urban adolescent girls, $\mathrm{n}_{\mathrm{r}}$ : Number of rural adolescent girls

Table 5.Association of Knowledge Scores with Socio-demographic Factors of Adolescent Girls of Urban School regarding Reproductive Health

\begin{tabular}{|c|c|c|c|c|c|c|c|}
\hline \multirow{2}{*}{ S. No. } & \multirow{2}{*}{$\begin{array}{c}\text { Demographic } \\
\text { Variables }\end{array}$} & \multicolumn{2}{|c|}{ Knowledge Score } & \multirow{2}{*}{ Total } & \multirow{2}{*}{$\begin{array}{l}\text { Chi-Square } \\
\text { Value }\left(\chi^{2}\right)\end{array}$} & \multirow{2}{*}{ df } & \multirow{2}{*}{ P Value } \\
\hline & & $<$ Median & $\geq$ Median & & & & \\
\hline \multirow{3}{*}{1.} & \multicolumn{7}{|c|}{ Age of student (years) } \\
\hline & $<15$ & 14 & 26 & 40 & \multirow{2}{*}{0.254} & \multirow{2}{*}{1} & \multirow{2}{*}{0.614} \\
\hline & $\geq 15$ & 15 & 35 & 50 & & & \\
\hline \multirow{3}{*}{2.} & \multicolumn{7}{|l|}{ Educational status } \\
\hline & Class IX & 11 & 36 & 47 & \multirow{2}{*}{3.502} & \multirow{2}{*}{1} & \multirow{2}{*}{0.061} \\
\hline & Class X & 18 & 25 & 43 & & & \\
\hline \multirow{3}{*}{3.} & \multicolumn{7}{|c|}{ Sensitisation programmes } \\
\hline & Attended & 22 & 43 & 65 & \multirow{2}{*}{0.283} & \multirow{2}{*}{1} & \multirow{2}{*}{0.595} \\
\hline & Not attended & 07 & 18 & 25 & & & \\
\hline \multirow{3}{*}{4.} & \multicolumn{7}{|c|}{ Educational status of father } \\
\hline & Up to secondary & 13 & 38 & 51 & \multirow{2}{*}{2.442} & \multirow{2}{*}{1} & \multirow{2}{*}{0.118} \\
\hline & Above secondary & 16 & 23 & 39 & & & \\
\hline \multirow{3}{*}{5.} & \multicolumn{7}{|c|}{ Educational status of mother } \\
\hline & Up to secondary & 20 & 48 & 68 & \multirow{2}{*}{1.006} & \multirow{2}{*}{1} & \multirow{2}{*}{0.316} \\
\hline & Above secondary & 09 & 13 & 22 & & & \\
\hline \multirow{3}{*}{6.} & \multicolumn{7}{|c|}{ Occupational status of father } \\
\hline & Non-service & 16 & 38 & 54 & ه15 & 1 & 0510 \\
\hline & Service & 13 & 23 & 36 & & & \\
\hline & Occupational status & f mother & & & & & \\
\hline 7. & Non-service & 27 & 59 & 86 & 0606 & 1 & 593 \\
\hline & Service & 02 & 02 & 04 & 0.000 & $\perp$ & 20.ני \\
\hline
\end{tabular}


Table 6.Association of Knowledge Score with Socio-demographic Characteristics of Adolescent Girls of Rural School regarding Reproductive Health

\begin{tabular}{|c|c|c|c|c|c|c|c|}
\hline \multirow{2}{*}{$\begin{array}{c}\text { S. } \\
\text { No. }\end{array}$} & \multirow{2}{*}{ Demographic Variables } & \multicolumn{2}{|c|}{ Knowledge Score } & \multirow{2}{*}{ Total } & \multirow{2}{*}{$\begin{array}{l}\text { Chi-Square } \\
\text { Value }\left(x^{2}\right)\end{array}$} & \multirow{2}{*}{ df } & \multirow{2}{*}{ P Value } \\
\hline & & $<$ Median & $\geq$ Median & & & & \\
\hline \multirow{3}{*}{1.} & \multicolumn{7}{|l|}{ Age of student (in years) } \\
\hline & $<15$ & 20 & 20 & 40 & \multirow{2}{*}{0.000} & \multirow{2}{*}{1} & \multirow{2}{*}{1.000} \\
\hline & $\geq 15$ & 25 & 25 & 50 & & & \\
\hline \multirow{3}{*}{2.} & \multicolumn{7}{|l|}{ Educational status } \\
\hline & Class IX & 27 & 19 & 46 & \multirow{2}{*}{3.621} & \multirow{2}{*}{1} & \multirow{2}{*}{0.057} \\
\hline & Class X & 17 & 27 & 44 & & & \\
\hline \multirow{3}{*}{3.} & \multicolumn{7}{|l|}{ Sensitisation programmes } \\
\hline & Attended & 11 & 13 & 24 & \multirow{2}{*}{0.227} & \multirow{2}{*}{1} & \multirow{2}{*}{0.634} \\
\hline & Not attended & 32 & 34 & 66 & & & \\
\hline \multirow{3}{*}{4.} & \multicolumn{7}{|l|}{ Educational status of father } \\
\hline & Up to secondary & 27 & 24 & 51 & \multirow{2}{*}{0.773} & \multirow{2}{*}{1} & \multirow{2}{*}{0.379} \\
\hline & Above secondary & 17 & 22 & 39 & & & \\
\hline \multirow{3}{*}{5.} & \multicolumn{7}{|l|}{ Educational status of mother } \\
\hline & Up to secondary & 35 & 35 & 70 & \multirow{2}{*}{0.156} & \multirow{2}{*}{1} & \multirow{2}{*}{0.693} \\
\hline & Above secondary & 09 & 11 & 20 & & & \\
\hline \multirow{3}{*}{6.} & \multicolumn{7}{|l|}{ Occupational status of father } \\
\hline & Non-service & 31 & 31 & 62 & 0098 & 1 & 0754 \\
\hline & Service & 13 & 15 & 28 & 0.098 & 1 & 0.134 \\
\hline & Occupational status of mot & & & & & & \\
\hline 7. & Non-service & 43 & 43 & 86 & 0956 & 1 & 0328 \\
\hline & Service & 01 & 03 & 04 & 0.950 & 1 & 0.320 \\
\hline
\end{tabular}

Table 7.Association of Attitude Score with Socio-demographic Characteristics of Adolescent Girls of Urban School regarding Reproductive Health

\begin{tabular}{|c|c|c|c|c|c|c|c|}
\hline \multirow{2}{*}{ S. No. } & \multirow{2}{*}{ Demographic Variables } & \multicolumn{2}{|c|}{ Knowledge Score } & \multirow{2}{*}{ Total } & \multirow{2}{*}{$\begin{array}{l}\text { Chi-Square } \\
\text { Value }\left(x^{2}\right)\end{array}$} & \multirow{2}{*}{ df } & \multirow{2}{*}{ P Value } \\
\hline & & $<$ Median & $\geq$ Median & & & & \\
\hline \multirow{3}{*}{1.} & \multicolumn{7}{|l|}{ Age of student (in years) } \\
\hline & $<15$ & 20 & 20 & 40 & \multirow{2}{*}{1.303} & \multirow{2}{*}{1} & \multirow{2}{*}{0.254} \\
\hline & $\geq 15$ & 19 & 31 & 50 & & & \\
\hline \multirow{3}{*}{2.} & \multicolumn{7}{|l|}{ Educational status } \\
\hline & Class IX & 20 & 27 & 47 & \multirow{2}{*}{0.669} & \multirow{2}{*}{1} & \multirow{2}{*}{0.413} \\
\hline & Class X & 22 & 21 & 43 & & & \\
\hline \multirow{3}{*}{3.} & \multicolumn{7}{|l|}{ Sensitisation programmes } \\
\hline & Attended & 30 & 35 & 65 & \multirow{2}{*}{0.758} & \multirow{2}{*}{1} & \multirow{2}{*}{0.384} \\
\hline & Not attended & 09 & 16 & 25 & & & \\
\hline \multirow{3}{*}{4.} & \multicolumn{7}{|c|}{ Educational status of father } \\
\hline & Up to secondary & 24 & 27 & 51 & \multirow{2}{*}{0.007} & \multirow{2}{*}{1} & \multirow{2}{*}{0.932} \\
\hline & Above secondary & 18 & 21 & 39 & & & \\
\hline
\end{tabular}




\begin{tabular}{|c|c|c|c|c|c|c|c|}
\hline \multirow{3}{*}{5.} & \multicolumn{7}{|c|}{ Educational status of mother } \\
\hline & Up to secondary & 30 & 36 & 66 & \multirow{2}{*}{1.168} & \multirow{2}{*}{1} & \multirow{2}{*}{0.280} \\
\hline & Above secondary & 14 & 10 & 24 & & & \\
\hline \multirow{3}{*}{6.} & \multicolumn{7}{|c|}{ Occupational status of father } \\
\hline & Non-service & 23 & 31 & 54 & \multirow{2}{*}{0.900} & \multirow{2}{*}{1} & \multirow{2}{*}{0.343} \\
\hline & Service & 19 & 17 & 36 & & & \\
\hline \multirow{3}{*}{7.} & \multicolumn{7}{|c|}{ Occupational status of mother } \\
\hline & Non-service & 39 & 47 & 86 & \multirow{2}{*}{1.350} & \multirow{2}{*}{1} & \multirow{2}{*}{0.245} \\
\hline & Service & 03 & 01 & 04 & & & \\
\hline
\end{tabular}

Table 8.Association of Attitude Score with Socio-demographic Characteristics of Adolescent Girls of Rural School regarding Reproductive Health

\begin{tabular}{|c|c|c|c|c|c|c|c|}
\hline \multirow{2}{*}{ S. No. } & \multirow{2}{*}{ Demographic Variables } & \multicolumn{2}{|c|}{ Knowledge Score } & \multirow{2}{*}{ Total } & \multirow{2}{*}{$\begin{array}{l}\text { Chi-Square } \\
\text { Value }\left(\chi^{2}\right)\end{array}$} & \multirow{2}{*}{ df } & \multirow{2}{*}{ P Value } \\
\hline & & $<$ Median & $\geq$ Median & & & & \\
\hline \multirow{3}{*}{1.} & \multicolumn{7}{|l|}{ Age of Student (in years) } \\
\hline & $<15$ & 19 & 21 & 40 & \multirow{2}{*}{0.110} & \multirow{2}{*}{1} & \multirow{2}{*}{0.740} \\
\hline & $\geq 15$ & 22 & 28 & 50 & & & \\
\hline \multirow{3}{*}{2.} & \multicolumn{7}{|l|}{ Educational status } \\
\hline & Class IX & 29 & 17 & 46 & \multirow{2}{*}{3.564} & \multirow{2}{*}{1} & \multirow{2}{*}{0.059} \\
\hline & Class X & 19 & 25 & 44 & & & \\
\hline \multirow{3}{*}{3.} & \multicolumn{7}{|l|}{ Sensitisation programmes } \\
\hline & Attended & 14 & 10 & 24 & \multirow{2}{*}{2.154} & \multirow{2}{*}{1} & \multirow{2}{*}{0.142} \\
\hline & Not attended & 27 & 39 & 66 & & & \\
\hline \multirow{3}{*}{4.} & \multicolumn{7}{|c|}{ Educational status of father } \\
\hline & Up to secondary & 24 & 27 & 51 & \multirow{2}{*}{0.107} & \multirow{2}{*}{1} & \multirow{2}{*}{0.743} \\
\hline & Above secondary & 17 & 22 & 39 & & & \\
\hline \multirow{3}{*}{5.} & \multicolumn{7}{|c|}{ Educational status of mother } \\
\hline & Up to secondary & 32 & 38 & 70 & \multirow{2}{*}{0.003} & \multirow{2}{*}{1} & \multirow{2}{*}{0.955} \\
\hline & Above secondary & 09 & 11 & 20 & & & \\
\hline \multirow{3}{*}{6.} & \multicolumn{7}{|c|}{ Occupational status of father } \\
\hline & Non-service & 30 & 32 & 62 & 061 & 1 & רבדות \\
\hline & Service & 11 & 17 & 28 & 0.044 & 1 & $0.4 \angle 2$ \\
\hline & Occupational status of $\mathrm{m}$ & ther & & & & & \\
\hline 7. & Non-service & 39 & 47 & 86 & 0032 & 1 & 0855 \\
\hline & Service & 02 & 02 & 04 & בנט & $\perp$ & ככס \\
\hline
\end{tabular}

\section{Discussion}

The present study is partially supported by a comparative study conducted by Dube $S$ et al. (2012) on the knowledge, attitude and practice regarding reproductive health among the urban and rural girls of 200 schools belonging to the age group of 15-29 years in Jaipur district. ${ }^{13}$ The study result showed that the knowledge regarding the average onset age of menstruation among the rural population is higher as compared to the urban population. It also showed that $41 \%$ of urban and $56 \%$ of rural girls received information about menarche, reproductive problems, etc. from their relatives. Both urban and rural adolescent girls did not seem to be aware of the scientific basis underlying reproduction and related issues. Considering their understanding of contraceptives, it is evident that $16 \%$ of urban and $23 \%$ of rural girls used contraceptives as precautionary expedients 
to avoid pregnancy, and $15 \%$ of urban and $12 \%$ of rural girls had the view that contraceptives are used for the prevention of STDs. It also revealed that $14 \%$ of urban and $10 \%$ of rural girls believed that HIV/ AIDS is transmitted through medical carelessness and $17 \%$ of urban and $20 \%$ of rural girls understood that the disease is spread through unsafe sex, and some percentage of the girls was not aware of the mode of spread of the disease and had unrealistic misconceptions.

The present study is supported by another study on the awareness of reproductive health and sexually transmitted diseases among adolescent girls of rural areas and urban slums in Bellary Taluk, conducted by Kappala Vinayaka Prasanna et al. (Dec 2014). ${ }^{14}$ It was found that about 50\% of urban and $37 \%$ of rural adolescent girls knew about menstruation before attaining it. However, only $7 \%$ of urban and $5 \%$ of rural adolescent girls knew about menstruation. The legal age of marriage for females was known by $47.5 \%$ of rural and $54.8 \%$ of urban adolescent girls. Rural adolescent girls had better knowledge about spacing between pregnancies (25.8\%) than urban adolescent girls $(20 \%)$ but urban girls had better knowledge about contraception (71\%) when compared to rural girls (22.8\%). Rural adolescent students had more knowledge about leucorrhoea (42.8\%) as compared to urban girls (35\%) but urban girls had better knowledge about the probable cause of white discharge (15\%) as compared to rural girls $(8.8 \%)$. In both urban and rural areas, more than half of adolescent girls were unaware of the reproductive health issues concerning menstruation, pregnancy, contraception, and STDs like white discharge. Statistically significant differences were found between the knowledge of urban and rural adolescents regarding menstruation before getting it, legal marriage age for females, and contraception, and the cause of white discharge.

Results of the present study are similar to those of a comparative study of knowledge regarding reproductive health among rural and urban adolescent girls in Bareilly district, conducted by Kumar P et al. (Apr 2019). ${ }^{15}$ The result revealed that nearly three-fourths of urban girls (156, $74.3 \%$ ) knew that menstruation is a normal physiological process. More urban girls $(88,41.9 \%)$ were aware of the uterus being the source of menstrual bleeding as compared to rural adolescents, and 195 (92.8\%) urban girls were aware of the average length of the menstrual cycle i.e. 3-5 days. More than half of the girls knew the importance of cleanliness during menstruation in both urban and rural areas. About 230 (54.7\%) adolescent girls were found to be aware of teenage pregnancy, 108 (87.8\%) urban adolescent girls had the knowledge of the normal age for childbearing i.e. > 20 years, and 192 (91.4\%) urban adolescent girls had the knowledge of the legal age of marriage for girls. The majority of girls knew the importance of small family norms and regular ANC checkups during pregnancy. 347 (82.6\%) subjects knew about oral contraceptive pills (OCP), 254 (60.5\%) knew about IUCD, and 237 (56.4\%) knew about condoms. However, only 39 (9.3\%) adolescent girls had knowledge of depot injections. So, it can be concluded that urban girls are more aware than rural girls. Most of the girls knew about spacing methods of contraception. Nearly half of the urban subjects were found to be aware of sex education as compared to lesser proportions of rural girls $(72,34.3 \%)$, and more than two-thirds of urban adolescent girls (67.1\%) mentioned the requirement of sex education. The gap in knowledge may be due to external environment like exposure to media, family status, and atmosphere of schools, but still, there is a need for increasing the awareness of adolescent girls towards reproductive health in both rural and urban areas.

\section{Limitations of the Study}

- Most of the subjects expressed that they received information regarding reproductive health from their parents which may not be solely true, because nowadays adolescents mostly depend on the internet for information

- There could be a chance that some questions were answered by the subjects based on their guess which did not reflect their actual knowledge. The researcher could not avoid this. This restricts the generalisation of the study findings

\section{Recommendations}

Based on the study findings, the following recommendations are made for further study:

- It can be conducted on a large sample, on a long term and periodic basis, and also in different settings

- It can be conducted as an experimental study

- It can be conducted on adolescent boys

\section{Conclusion}

There are many challenges faced by young people regarding their reproductive health depending on the cultural as well as geographical circumstances. For all adolescents, the necessity of accurate information, indulgent counselling, and affordable as well as accessible services is paramount in overcoming these challenges and helping them to avoid unwanted pregnancies and to look after their sexual health. Thus, it is highly essential to impart quality education regarding reproductive health including menstruation, fertilization and pregnancy, contraception, and sexually transmitted infections to urban and rural adolescent girls and to make them aware of the physical, physiological, and social changes that happen through childhood and adulthood.

\section{Acknowledgement}

We thank all the adolescent girls who participated in the 
study since without them this study would not have been possible. The authors thank all the faculties of College of Nursing, BSMC, Bankura for their guidance and support. The authors are also grateful to authors/ editors/ publishers of all those articles, journals, and books from where the literature for this article has been reviewed and discussed.

\section{Source of Funding: Self \\ Conflict of Interest: None}

\section{References}

1. Malleshappa K, Krishna S, Nandini C. Knowledge and attitude about reproductive health among rural adolescent girls in Kuppam Mandal: An intervention study. Biomed Res. 2011;22(3):305-10.

2. Menzil M, Deepa LN. Study of the knowledge regarding reproductive health among the second PUC students from the colleges of Bangalore city. Int J Comm Med Public Health. 2018;5(6):2301-7. [Google Scholar]

3. Shankar P, Dudeja P, Gadekar T, Mukherji S. Reproductive health awareness among adolescent girls of a government school in an urban slum of Pune city. Med J D Y Patil Univ. 2017;10:133-7. [Google Scholar]

4. Meena JK, Verma A, Kishore J, Ingle GK. Sexual and reproductive health: knowledge, attitude and perceptions among young unmarried male residents of Delhi. Int J Repr Med. 2015;431-60. [Google Scholar]

5. Jain $M$, Jain S, Patil S, Bang A. A study on knowledge attitude and practice of contraception in school going children in Wardha District in central India. Int J Reprod Contracep Obstet Gynecol. 2014;3(4):903-8. [Google Scholar]

6. Kumar R, Goyal A, Singh P, Bhardwaj A, Mittal A, Yadav SS. Knowledge attitude and perception of sex education among school going adolescents in Ambala, District Haryana, India: a cross-sectional study. J Clin Diagn Res. 2017 Mar;11(3):LC01-LC04. [PubMed] [Google Scholar]

7. Gaferi SM, Al-Harbi MF, Yakout SM, Soliman AT. Knowledge attitude and practice related to reproductive health among female adolescents. J Nurs Edu Prac. 2018;8(8):53-65. [Google Scholar]

8. Khanal P. Adolescents knowledge and perception of sexual and reproductive health and services-a study from Nepal [thesis]. Institute of Public Health and Clinical Nutrition, University of Eastern Finland, Kuopio; 2016. [Google Scholar]

9. Datta A, Manna N, Datta M, Sarkar J, Baur B, Datta S. Menstruation and menstrual hygiene among adolescent girls of West Bengal, India: a school based comparative study. Global J Med Public Health. 2012;5:50-7.

10. Senapathi P, Kumar H. A comparative study of menstrual hygiene management among rural and urban adolescent girls in Mangaluru, Karnataka. Int
J Comm Med Public Health. 2018 Jun;5(6):2548-56. [Google Scholar]

11. Vijayageetha M, Narayanamurthy MR, Vidya GS, Renuka M. Knowledge and attitude on HIV/AIDS among adolescent school children in urban Mysuru, Karnataka, India: a cross sectional study. Int J Comm Med Public Health. 2016 May;3(5):1224-8.

12. Grover S, Garg N, Rupali R, Kaur B. Awareness about reproductive health, contraceptive methods, STDs including HIV/AIDS, and HPV vaccine, among adolescent girls in district Faridkot in Punjab. Int J Reprod Contrac Obstet Gynecol. 2017;6:2003-9.

13. Dube S, Sharma K. Knowledge, attitude and practice regarding reproductive health among urban and rural girls: a comparative study. Stud Ethno-Med. 2012;6(2):85-94. [Google Scholar]

14. Kappala VP, Doddaiah V, Raghavendra B, Nagammanavar R, Kamble S, Goud TG, Chendaki VS. A study of awareness of reproductive health and sexually transmitted diseases among adolescent girls of rural areas and urban slums in Bellary Taluk. Int J Health Sci Res. 2014;4(12):70-8. [Google Scholar]

15. Kumar P, Saxena S, Gupta SB, Agarwal N, Imtiaz D. A comparative study of knowledge regarding reproductive health among rural \& urban adolescent girls in district Bareilly. Natl J Community Med. 2019;10(4):212-7. [Google Scholar] 